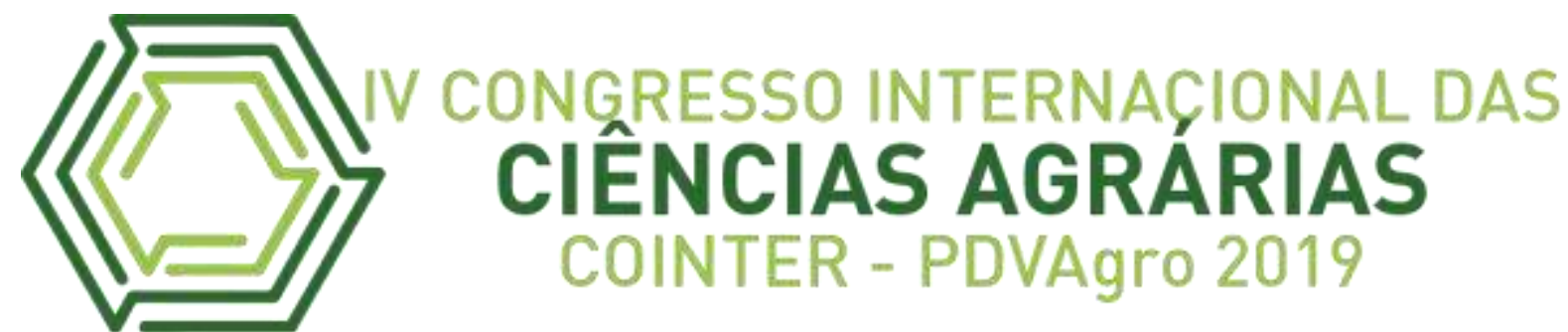

\title{
ANÁLISE SENSORIAL DE IOGURTES DA COOPERATIVA AGROPECUÁRIA DO SALGADO PARAENSE: UMA ALTERNATIVA DE COMERCIALIZAÇÃO NO MUNICÍPIO DE CASTANHAL, ESTADO DO PARÁ
}

\section{ANÁLISIS SENSORIAL DE YOGURES DE LA COOPERATIVA AGRÍCOLA DE SALGADO PARÁ: UNA ALTERNATIVA DE COMERCIALIZACIÓN EN EL MUNICIPIO DE CASTANHAL, ESTADO DE PARÁ.}

\section{SENSORY ANALYSIS OF YOGHURTS OF AGRICULTURAL COOPERATIVE OF THE SALGADO PARÁ: AN ALTERNATIVE MARKETING IN THE MUNICIPALITY OF CASTANHAL, STATE OF PARÁ}

\author{
Apresentação: Comunicação Oral
}

\begin{abstract}
Cleidson Barbosa Favacho ${ }^{1}$; Leandro Jose de Oliveira Mindelo ${ }^{2}$; Robson da Silveira Espíndola ${ }^{3}$; Wagner Luiz Nascimento do Nascimento ${ }^{4}$; Maria Regina Sarkis Peixoto Joele ${ }^{5}$

DOI:https://doi.org/10.31692/2526-7701.IVCOINTERPDVAgro.2019.0151
\end{abstract}

\begin{abstract}
Resumo
As indústrias de alimentos lançam cada vez mais novos produtos no mercado consumidor por diversos fatores, dentre eles pode-se citar os consumidores que estão cada vez mais exigentes quanto a qualidade sensorial dos produtos. A Cooperativa Agropecuária do Salgado Paraense (CASP) é um empreendimento que atua no processamento de leite para a produção de iogurtes de diferentes sabores para atender demandas de escolas da cidade de Vigia de Nazaré - PA. Com tudo, no período de férias escolares, a CASP não possui um mercado alternativo para a comercialização da produção. Um dos primeiros passos para inserção de um produto no mercado é conhecimento de sua aceitabilidade, intenção de compra e do mercado. O objetivo do presente trabalho foi aplicar a análise sensorial e a intenção de compra com os iogurtes produzidos pela CASP, afim de identificar a viabilidade de inserção desses produtos no mercado do município de Castanhal, Estado do Pará. Foi realizada análise sensorial com 103 provadores não treinados, utilizando escala hedônica de 9 pontos para os atributos aroma, textura e sabor, ao quais em seguida, indicaram sua intenção de compra em escala estruturada de 5 pontos. Em seguida, observou-se os valores de iogurtes de 03 marcas diferentes comercializados em 07 supermercados de Castanhal. Os resultados mostram que a
\end{abstract}

\footnotetext{
${ }^{1}$ Engenharia de Alimentos, IFPA-Castanhal, cleidsonbfavacho@gmail.com

2 Engenharia de Alimentos, IFPA-Castanhal, leandromindelo50@gmail.com

${ }^{3}$ Engenharia de Alimentos, IFPA-Castanhal, robsonespindola4@gmail.com

${ }^{4}$ Engenheiro Agrônomo, MsC. IFPA-Castanhal, wagnerlnnascimento@gmail.com

${ }^{5}$ Professora, Drª, IFPA-Castanhal, reginajoele@ hotmail.com
} 
aceitabilidade dos iogurtes sabores abacaxi, coco e cupuaçu obtiveram aceitação acima de 80\%, ou seja, índice considerado "bom". O sabor milho verde obteve índice de aceitação abaixo do mínimo para ser considerado um produto aceito. Os índices de intenção de compra dos iogurtes sabores abacaxi, coco e cupuaçu mostram o potencial mercadológico dos produtos. Os preços dos iogurtes comercializados no município, estão bem acima dos preços comercializados pela CASP. Assim, infere-se que a inserção dos iogurtes com sabor abacaxi, coco e cupuaçu no mercado consumidor do município de Castanhal é viável tanto pela qualidade - aceitação, quanto pelo preço praticado pela cooperativa na comercialização do produto. Por outro lado, o iogurte sabor milho verde foi rejeitado pelos provadores. Desse modo, esse produto é inviável para inserção no mercado.

Palavras-Chave: Aceitabilidade, Intenção de compra, Pesquisa de mercado, Iogurte.

\section{Resumen}

Las industrias alimentarias cada vez más el lanzamiento de nuevos productos en el mercado de los consumidores por varios factores, entre ellos podemos mencionar a los consumidores que son cada vez más exigentes en la calidad sensorial de los productos. La cooperativa agrícola de la Salgado Pará (CASP) es una empresa que opera en el sector de la transformación de la leche para la producción de yogurt de diferentes sabores para satisfacer las demandas de las escuelas de la ciudad de Vigia de Nazaré - PA. Con todo, en el periodo de vacaciones escolares, el CASP no tiene un mercado alternativo para la comercialización de la producción. Uno de los primeros pasos para la inserción en el mercado de un producto es consciente de su aceptabilidad, intención de compra y el mercado. El objetivo de este estudio fue aplicar el análisis sensorial y la intención de compra con el yogur producida por el CASP, a fin de determinar la viabilidad de la inserción de estos productos en el mercado de la ciudad de Castanhal, Estado de Pará. El análisis sensorial se realizó con 103 catadores inexperto, utilizando la escala hedónica de 9 puntos para los atributos de aroma, textura y sabor, que indicó su intención de compra estructurado en escala de 5 puntos. A continuación, se observó que los valores de los yogures de 03 diferentes marcas comercializadas en 07 supermercados de Castanhal. Los resultados muestran que la aceptabilidad de los yogures sabores de piña, coco y cupuaçu obtenido aceptación por encima del 80\%, es decir, el índice se considera "bueno". El sabor del maíz verde obtenido aceptación tasa por debajo del mínimo para ser considerado como un producto aceptado. Los índices de intención de compra de yogures sabores de piña, coco y cupuassu muestran el potencial de comercialización de productos. Los precios de los yogures comercializados en el municipio, están muy por encima de los precios comercializados por el CASP. Por lo tanto, se puede inferir que la inserción del yogur con sabor de piña, coco y cupuaçu en el mercado de los consumidores de la ciudad de Castanhal es viable, tanto por la calidad - aceptación, y el precio cobrado por la cooperativa en la comercialización del producto. Por otro lado, el yogur sabor maíz verde fue rechazada por los catadores. De esta manera, este producto no es viable para la inserción en el mercado.

Palabras Clave: la aceptabilidad, intención de compra, investigación de mercado, yogur.

\section{Abstract}

The food industries increasingly launching new products on the consumer market by several factors, among them we can mention those consumers who are increasingly demanding as the 
sensory quality of products. The Agricultural Cooperative of the Salgado Pará (CASP) is an undertaking that operates in the processing of milk for the production of yogurt of different flavors to meet demands of schools of the city of Vigia de Nazare - PA. With everything in the school holiday period, the casp does not have an alternative market for the commercialization of production. One of the first steps for insertion of a product on the market is aware of its acceptability, purchase intent and the market. The objective of this study was to apply the sensory analysis and purchase intent with the yoghurt produced by CASP, in order to identify the feasibility of inserting these products on the market of the municipality of Castanhal, Pará State. Sensory analysis was performed with 103 untrained tasters, using hedonic scale of 9 points for the attributes aroma, texture and flavor, which then indicated its intention to purchase in structured scale of 5 points. Then, it was observed that the values of yoghurts of 03 different brands marketed in 07 supermarkets in Castanhal. The results show that the acceptability of yoghurts flavors of pineapple, coconut and cupuaçu obtained acceptance above $80 \%$, i.e., Index is considered "good". The flavor green maize obtained acceptance rate below the minimum to be considered a product accepted. The indexes of purchase intention of yoghurts flavors of pineapple, coconut and cupuassu show the potential marketing of products. The prices of yoghurts marketed in the municipality, are well above the prices marketed by CASP. Thus, it can be inferred that the insertion of the yogurt with flavor pineapple, coconut and cupuaçu on the consumer market of the city of Castanhal is viable both for the quality - acceptance, and the price charged by the cooperative in the marketing of the product. On the other hand, the yoghurt flavor green corn was rejected by the tasters. In this way, this product is not viable for insertion in the market.

Keywords: Acceptability, Purchase intention, Market research, Yorgut.

\section{Introdução}

As indústrias de alimentos nunca lançaram no mercado tantos produtos novos e diversificados como vêm ocorrendo nos últimos anos no Brasil. Esta inovação vem acontecendo em virtude de diversos fatores como o desenvolvimento tecnológico, o crescimento da concorrência, a competitividade do setor, das prateleiras dos supermercados, que recebem diariamente novos produtos e das exigências dos consumidores que incorporaram novos valores às suas preferências (BARBOZA, 2013).

De acordo com Minim (2010), as indústrias de alimentos têm procurado identificar e atender os anseios dos consumidores em relação a inovação e a qualidade sensorial de seus produtos, tanto para se manterem, quanto para ampliarem o seu mercado.

Nesse contexto, encontra-se a Cooperativa Agropecuária do Salgado Paraense (CASP), que é um empreendimento que atua principalmente no processamento de leite para a produção de derivados, como iogurtes de diferentes sabores. A produção é bastante elevada para atender a demanda das escolas de ensino básico do município de Vigia de Nazaré - Pará e outras cidades 
via Programa Nacional de Alimentação Escolar (PNAE) e Programa de Aquisição de Alimentos (PAA).

A CASP produz atualmente iogurtes de 06 (seis) sabores diferentes para fornecer às escolas. Porém, essa demanda cessa durante o período de férias escolares e a produção não tem um mercado consumidor alternativo para a comercialização dos iogurtes, o que traz transtornos e prejuízos para os cooperados.

De acordo com Trentin et al. (2018), um dos primeiros passos para a inserção de um produto no mercado consumidor é o conhecimento da aceitação sensorial, intenção de compra pelos consumidores e pesquisa de mercado, o qual o produto vai ser inserido. Para tanto, é necessária uma aplicação da análise sensorial como ferramenta de obtenção de tais informações acerca da qualidade sensorial do produto analisado e uma pesquisa de mercado para analisar os preços dos produtos da concorrência.

Nesse tipo de análise, pode-se avaliar a qualidade da textura, o sabor, a estabilidade de armazenamento entre outros. Para alcançar o objetivo específico de cada análise, são elaborados métodos de avaliação diferenciados, visando a obtenção de respostas mais adequadas ao perfil pesquisado do produto. Esses métodos apresentam características que se moldam com o objetivo da análise. O resultado, que deve ser expresso de forma específica conforme o teste aplicado e estudado estatisticamente obtendo, dessa forma, a viabilidade do produto (TEIXEIRA, 2009).

A utilização de técnicas de pesquisa de mercado pode auxiliar a tarefa de desenvolver ou aprimorar produtos, servindo como mecanismo de captação das necessidades dos clientes, monitoramento de seus hábitos e atitudes e de avaliação de conceitos, protótipos e produtos para inserção no mercado consumidor (POLIGNANO, 2001).

Na perspectiva de ampliar as possibilidades de comercialização da CASP, o objetivo do presente trabalho foi realizar análise sensorial, intenção de compra de iogurtes produzidos pela cooperativa e pesquisar o mercado para saber a viabilidade de inserção desses produtos no mercado consumidor.

\section{Fundamentação Teórica}

Iogurte

Entende-se por leites fermentados os produtos adicionados ou não de outras substâncias alimentícias, obtidas por coagulação e diminuição do pH do leite, ou reconstituído, adicionado 
ou não de outros produtos lácteos, por fermentação láctica mediante ação de cultivos de microrganismos específicos. Estes microrganismos específicos devem ser viáveis, ativos e abundantes no produto final durante seu prazo de validade. $\mathrm{O}$ iogurte, cuja fermentação se realiza com cultivos protosimbióticos de Streptococcus salivarius subsp. thermophilus e Lactobacillus delbrueckii subsp. Bulgaricus, aos quais se podem acompanhar, de forma complementar, outras bactérias ácido-lácticas que, por sua atividade, contribuem para a determinação das características do produto final (BRASIL, 2007).

O iogurte é um dos poucos alimentos conhecidos e consumidos a mais de 4.500 anos. A Bulgária foi um dos primeiros países a consumi-lo, e o divulgou para o restante do mundo. Nos anos 1950 teve sua popularidade aumentada ao considerá-lo um alimento bom para a saúde e para o corpo. Desde então, esse produto foi ganhando espaço no dia a dia, passando a fazer parte dos hábitos alimentares de muitas pessoas (MORAES, 2004).

\section{Análise Sensorial}

A análise sensorial é definida pela Associação Brasileira de Normas Técnicas (ABNT, 1993) como a disciplina científica usada para evocar, medir, analisar e interpretar reações das características dos alimentos e materiais como são percebidas pelos sentidos da visão, olfato, paladar, tato e audição. É uma ciência que objetiva, principalmente, estudar as percepções, sensações e reações do consumidor sobre as características dos produtos, incluindo sua aceitação ou rejeição.

Milagres (2015) relata sobre testes afetivos, onde são avaliadas as diferenças sensoriais entre dois ou mais produtos. Ou seja, devem colher a opinião do consumidor para trazer uma avaliação quanto ao gosto do consumidor, ou seja, se ele gosta ou não daquele produto, tentando entender as preferências do público-alvo. Os testes afetivos requerem equipes com grande número de participantes e que representem a população de consumidores atuais e/ou potenciais do produto.

A análise sensorial tem se mostrado uma importante ferramenta nesse processo, envolvendo um conjunto de técnicas diversas elaboradas com o intuito de avaliar um produto quanto à sua qualidade sensorial, em várias etapas de seu processo de fabricação (TEIXEIRA, 2009).

Quando se fala em alimentos, há a necessidade de saber a aceitação do produto em relação aos seus atributos. Na indústria de alimentos isso não é diferente, antes de lançar um 
produto no mercado consumidor necessita-se saber a aceitação dos atributos do mesmo para assim ter noção do sucesso do produto no mercado. Dessa forma, a análise sensorial intervém diretamente no desenvolvimento de novos produtos lançados no mercado (TRENTIN et al., 2018).

A análise sensorial pode auxiliar, de forma direta ou indireta, as empresas do setor alimentar num vasto leque de atividades, entre as quais, desenvolvimento, melhoramento e reformulação de produtos, determinação da vida útil, controlo de qualidade, aceitabilidade pelos consumidores, como também monitoramento da concorrência e na pesquisa de mercado (SILVA, 2015).

\section{Pesquisa de mercado}

Pesquisa de mercado é a capacidade de identificar, coletar, analisar e disseminar informações de forma sistemática e objetiva, visando melhorar as tomadas de decisão relacionadas à identificação e resolução de problemas e/ou oportunidades de uma determinada empresa (MALHOTRA, 2001). Podendo ser utilizados para outras entidades como os empreendimentos de economia solidária.

Entender as demandas dos consumidores e a oferta de produtos pela indústria de alimentos tem se tornado algo constante na sociedade. É comum encontrar nos supermercados de pequeno, médio e grande porte, representantes de diversas empresas com os mais variados tipos de produtos, apresentando aos clientes do estabelecimento novas tendências, garantia ou simplesmente, produtos que atendam a demanda de um novo nicho de mercado como os produtos orgânicos e/ou agroecológico que trazem a ideia de sustentabilidade.

Também se pode acrescenta que, uma pesquisa de mercado deve ser objetiva. Durante a pesquisa deve sempre procurar fornecer informações precisas que reflitam uma situação verdadeira a ser executada de forma imparcial. Ou seja, o responsável pela pesquisa de mercado, deve procurar ser imparcial, isto é, isento de inclinações pessoais ou pré-conceitos para não influenciar os resultados da pesquisa (SPAREMBERGER, 2008). Além disso, a pesquisa de mercado visa identificar a presença de possíveis espaços e/ou canais de comercialização para determinados produtos (MALHOTRA, 2001).

Nesse sentido, a pesquisa de mercado vem com o objetivo de identificar essa nova tendência de mercado, a qual pode considerar características do produto ou analisar informações mais diretas como o valor de determinado produto no mercado. Conforme Kotler 
(2000), as pesquisas de mercado podem acontecer por meio de grupo de foco, pesquisa por observação, levantamentos, dados comportamentais e pesquisa experimental, tendo como instrumentos o questionário e os instrumentos mecânicos.

O método de pesquisa por observação responde de maneira satisfatória a particularidades de algumas questões de pesquisa e deve apresentar algumas características específicas, como: possibilidade de coleta de dados durante longos períodos; coletar as informações de maneira discreta e reservada, a fim de evitar que as respostas sejam inverídicas; coletar informações que possibilitem uma predição do fenômeno e produzir dados que possam ser aplicados em larga escala, ou seja, em vez de trazer regularidades de uma característica para generalização, deve ser passível de, se necessário, comparar com diversos outros casos (GIL, 2008).

Pode-se perceber com essa definição que a pesquisa de mercado é uma ferramenta essencial para manter a impressa informada sobre as variáveis de preços, variáveis essas imprescindíveis para a vida saudável de um negócio, seja ele de pequeno, médio ou grande porte, em processo de idealização, implementação ou expansão (ANTÔNIO, 2008).

De acordo com Tinoco (2008), as pesquisas têm estudado o preço percebido por clientes de produtos. As pesquisas encontradas na literatura sobre percepção de preço estão direcionadas ao estudo da relação entre o preço e qualidade percebida nos produtos e outros determinantes da satisfação do cliente.

A qualidade é considerada um fator primordial, onde o consumidor faz sua avaliação acerca do produto ou serviço desejado, avaliando seus pontos qualitativos, esses pontos são sempre destacados pelas empresas, em face da concorrência tão acirrada atualmente em qualquer segmento de mercado. A qualidade deve ser vista como o potencial intrínseco aos atributos do produto, como a qualidade sensorial de um produto artesanal, ressaltando que a qualidade percebida é certamente dependente da função de utilidade para o cliente em relação ao nível de qualidade fornecido (TREZ, 2005).

\section{Metodologia}

\section{Lócus da Pesquisa}

O presente trabalho apresenta uma abordagem quali-quantitativa em um estudo de caso realizado no município de Castanhal, localizado na região metropolitana de Belém, capital do Estado do Pará. O município está localizado a aproximadamente $73 \mathrm{~km}$ de Belém (figura 01). 
Figura 01: localização do município onde foi realizado o trabalho.

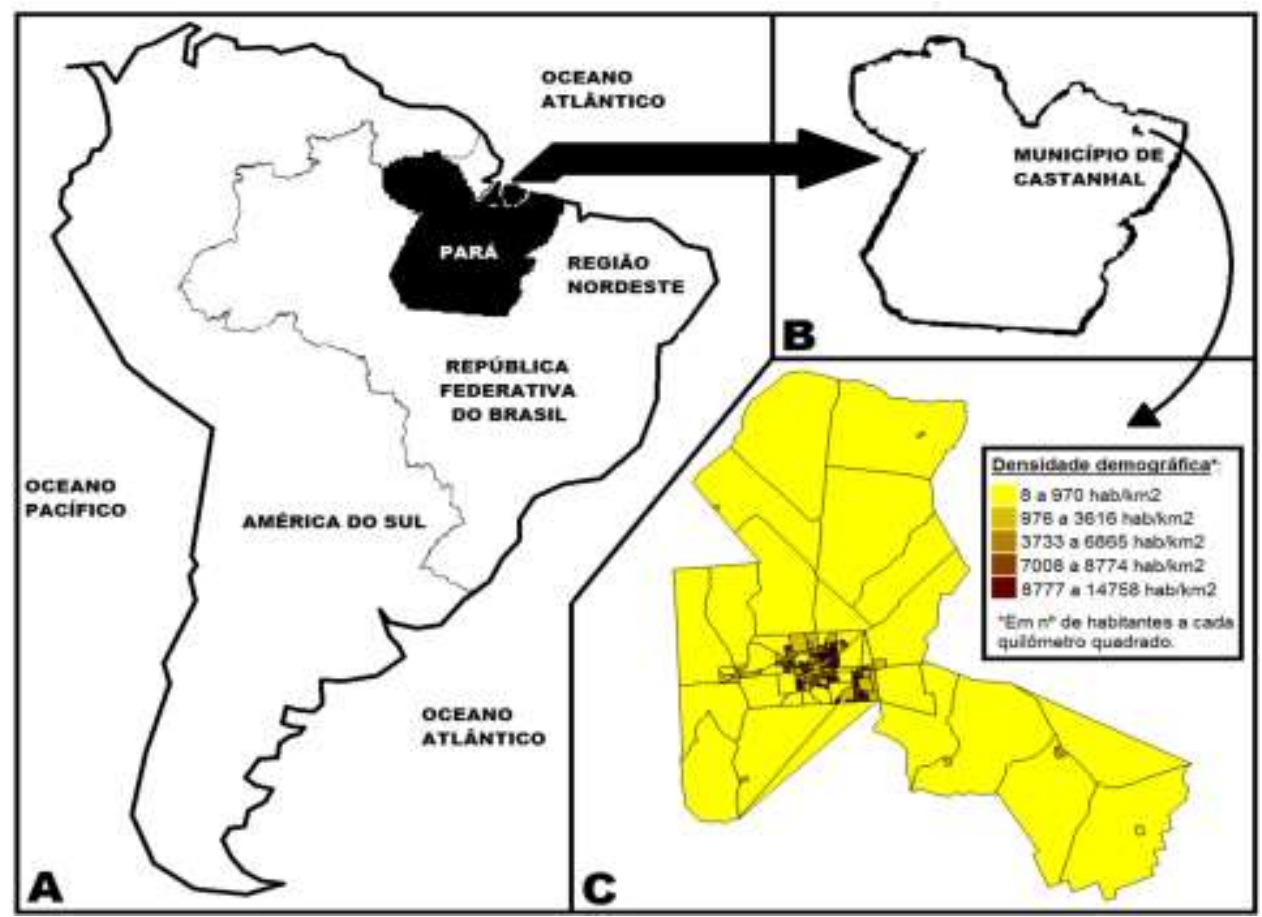

Fonte: RUAS, 2014.

De acordo com o IBGE (2018), o município de Castanhal possui área de 1.030,261 km² e população estimada de 200.793 habitantes, com PIB per capita de R $\$ 18.709,66$.

A sede/agroindústria da CASP está localizada no município de Vigia de Nazaré, distante $60 \mathrm{~km}$ de Castanhal.

\section{Coleta das amostras}

Foram coletados na agroindústria da cooperativa 3600g de iogurtes sabores abacaxi, coco, cupuaçu e milho verde e transportadas para Castanhal sob refrigeração em uma caixa de poliestireno.

\section{Análise Sensorial}

O teste sensorial foi realizado no Laboratório de Análise Sensorial do Instituto Federal de Educação, Ciência e Tecnologia do Pará - Campus Castanhal. Participaram do teste 103 provadores aleatórios com idades entre 14 a 25 anos, os quais degustaram 04 (quatro) amostras de $30 \mathrm{~g}$ de iogurtes sabores abacaxi, coco, milho verde e cupuaçu e atribuíram uma nota em escala hedônica de 9 pontos (onde $9=$ gostei muitíssimo e $1=$ desgostei muitíssimo) para os atributos aroma, textura e sabor, em uma ficha previamente disposta (figura 02). 
Em seguida, os provadores indicaram sua intenção de compra em relação aos produtos analisados, optando por um valor numa escala estruturada de 5 pontos $(5=$ certamente compraria e 1 = certamente não compraria).

Figura 02: ficha da escala hedônica e escala de intenção de compra

\section{FICHA DE ANÁLISE SENSORIAL}

Nome: Idade:

Data:

Prove as amostras de iogurte e avalie cada uma usando a escala abaixo para descrever o quanto gostou ou desgostou do produto:

9 - Gostei muitissimo

8 - Gostei muito

7 - Gostei regularmente

6 - Gostei ligeiramente

5 - Indiferente

4-Desgostei ligeiramente

3 - Desgostei regularmente

\begin{tabular}{|c|c|c|c|}
\cline { 2 - 4 } \multicolumn{1}{c|}{} & \multicolumn{3}{c|}{ Atributos } \\
\hline Amostras & Aroma & Textura & Sabor \\
\hline Abacaxi & & & \\
\hline Coco & & & \\
\hline Cupuaçu & & & \\
\hline Milho Verde & & & \\
\hline
\end{tabular}

2 - Desgostei muito

1 - Desgostei muitissimo

Indique a sua intenção de compra em relação as amostras provadas seguindo a escala abaixo:

5 - Certamente compraria

4 - Provavelmente compraria

3 - Tenho dúvidas se compraria

2 - Provavelmente não compraria

1 - Certamente não compraria

\begin{tabular}{|c|c|}
\hline Amostra & Valor \\
\hline Abacaxi & \\
\hline Coco & \\
\hline Cupuaçu & \\
\hline Milho Verde & \\
\hline
\end{tabular}

Comentários (Opcional):

Fonte: Própria (2019)

O índice de aceitabilidade (IA) dos atributos dos iogurtes foi obtido através da média de cada atributo dividida pela maior nota da escala hedônica e multiplicado por 100, para obter-se a porcentagem, como mostra a equação a baixo, de acordo com Bastos (2014).

$$
\mathrm{IA}=\frac{\text { média do atributo }}{9} * 100
$$


Para a determinação da intenção de compra dos iogurtes, os valores obtidos na escala estruturada foram somados para obtenção do percentual de cada item analisado.

\section{Pesquisa de mercado}

A pesquisa de mercado foi realizada pelo método da observação e identificação, tendo como variável o valor em reais $(\mathrm{R} \$)$ e a quantidade $(\mathrm{g})$ dos iogurtes durante a pesquisa. Para determinar essas vaiáveis, foi considerado o volume $(\mathrm{g})$ dos iogurtes comercializados pela Cooperativa Agropecuária do Salgado Paraense - CASP. Os volumes comercializados pela CASP são de $900 \mathrm{~g}$ e $200 \mathrm{~g}$.

De acordo com a definição de mercado, foi identificado o produto que se buscava analisar, neste caso os iogurtes de $900 \mathrm{~g}$ e $170 \mathrm{~g}$. Posteriormente, foram coletados os valores no em 05 Supermercados Grande Porte (SGP) e 02 Supermercados Pequeno Porte (SPP), no município de Castanhal. Para tanto, foi considerado o valor quantitativo do produto de três marcas distintas, sendo uma regional e duas nacionais. Com os dados coletados nos SGP e SPP, em, realizou-se a tabelamento e análise para aferições acerca das informações coletadas durante a pesquisa.

\section{Resultados e Discussão}

\section{Aceitabilidade dos iogurtes}

A aceitação de um produto é entendida pelo conjunto relativo à primeira impressão causada pelo produto como um todo, podendo representa-la pela média das notas das outras características avaliadas (GOMES, 2009).

Quando se expressa aceitação de um produto, Dutcosky (2007) estabelece um índice de aceitabilidade no mínimo de $70 \%$ para que o produto seja considerado aceito, em termos de suas propriedades sensoriais. Os resultados obtidos nos testes com os iogurtes da CASP são apresentados nos gráficos 01, 02 e 03.

\section{Aceitabilidade do atributo aroma}

Percebe-se que no atributo aroma (gráfico 01) todos os sabores de iogurtes estão dentro do valor mínimo permitido. Dessa forma, esses produtos foram classificados aceitos pelos consumidores nesse quesito. 
Gráfico 01: aceitabilidade do atributo aroma.

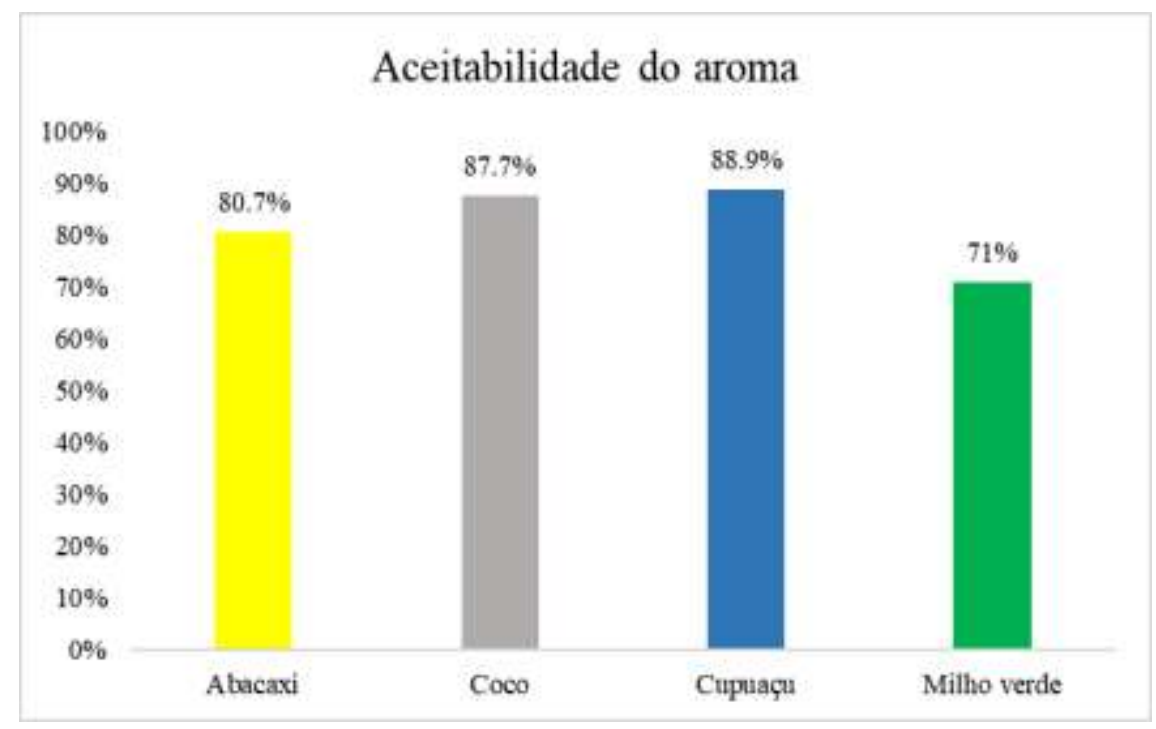

Fonte: Própria (2019)

Andrade et al. (2017) estudaram a aceitação sensorial de iogurte artesanal simbiótico de dois tipos, o natural e o acrescido de maracujá, em ambos foram avaliados o aroma e o sabor. O iogurte acrescido de maracujá apresentou melhor aceitabilidade no quesito aroma. Nesse presente estudo, o atributo aroma também influenciou positivamente na aceitação sensorial de todos os iogurtes analisados.

\section{Aceitabilidade do atributo textura}

O gráfico 02 demonstra os iogurtes sabores abacaxi, coco e cupuaçu obtiveram índice de aceitação acima de $80 \%$. Sendo assim, todos estão dentro do limite de aceitabilidade. O iogurte sabor milho verde, obteve índice de $65,6 \%$, estando fora do mínimo permitido, sendo classificado como não aceito.

De acordo com Antunes (2008), foi observado que a textura do iogurte é um dos fatores que mais influenciam na análise sensorial, sendo que o iogurte é relacionado a um alimento "viscoso".

Os provadores relataram nos comentários da ficha de análise sensorial, que o iogurte sabor milho verde apresentava uma textura "fina", sendo esse o fator que resultou na não aceitação do atributo desse iogurte. Assim, percebe-se que apenas três dos iogurtes comercializados pela CASP estão coma a textura aceitável para o consumidor. 
Gráfico 02: índice de aceitabilidade do atributo textura

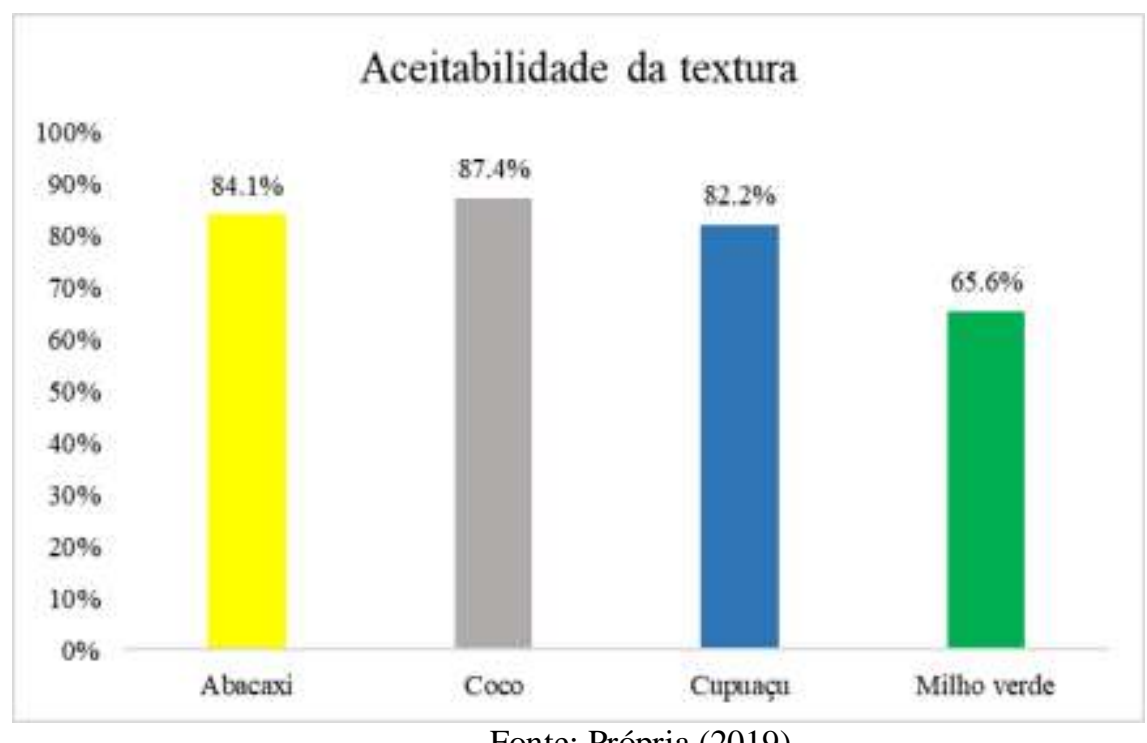

Fonte: Própria (2019)

\section{Aceitabilidade do atributo sabor}

No gráfico 03, observa-se que, novamente, apenas os iogurtes sabores abacaxi, coco e cupuaçu foram aceitos. O iogurte sabor milho verde obteve índice de $61,4 \%$, ficando abaixo do valor mínimo necessário para ser considerado aceito. Portanto, nesse caso, o iogurte foi classificado como não aceito.

Gráfico 03: aceitabilidade do atributo aroma.

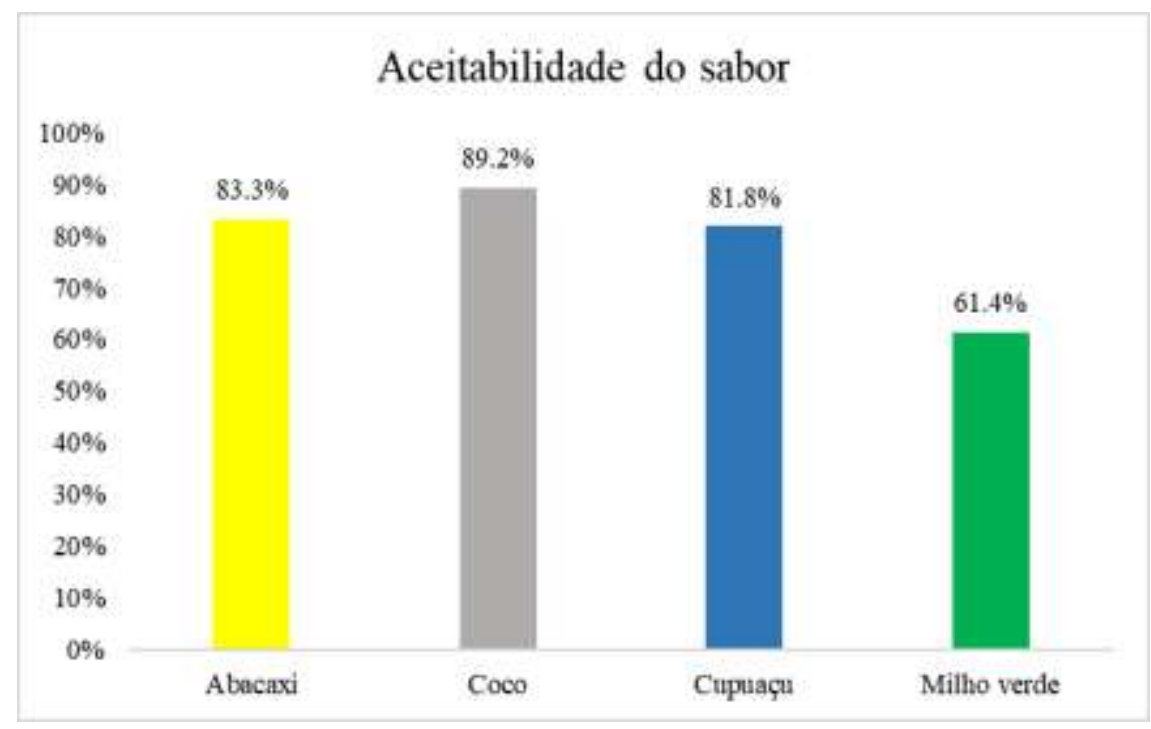

Fonte: Própria (2019)

Reis et al. (2009) relataram que a adição acentuada de saborizantes artificias na saborização de iogurte influencia negativamente na aceitação sensorial, chegando a ser rejeitado pelos provadores. Nesse sentido, o baixo índice de aceitabilidade do iogurte sabor milho verde 
se deve pelo fato do intenso aroma apresentado, como foi comentado pelos provadores nos comentários da ficha de análise sensorial.

Dessa forma, os iogurtes sabores abacaxi, coco e cupuaçu estão dentro dos critérios considerados aceitos quanto sua aceitabilidade expressa nos quesitos aroma, textura e sabor, na qual as três amostras se encaixam no quesito "bom" em índice de aceitação.

\section{Índice de intenção de compra dos iogurtes}

De modo geral, é explicito que há um alto índice de intenção de compra em três sabores de iogurtes da CASP, como mostra o gráfico 04. Esses índices demostram que esses produtos são de grande interesse para os consumidores, devido as qualidades sensoriais apresentadas pelos produtos.

Gráfico 04: intenção de compra dos iogurtes

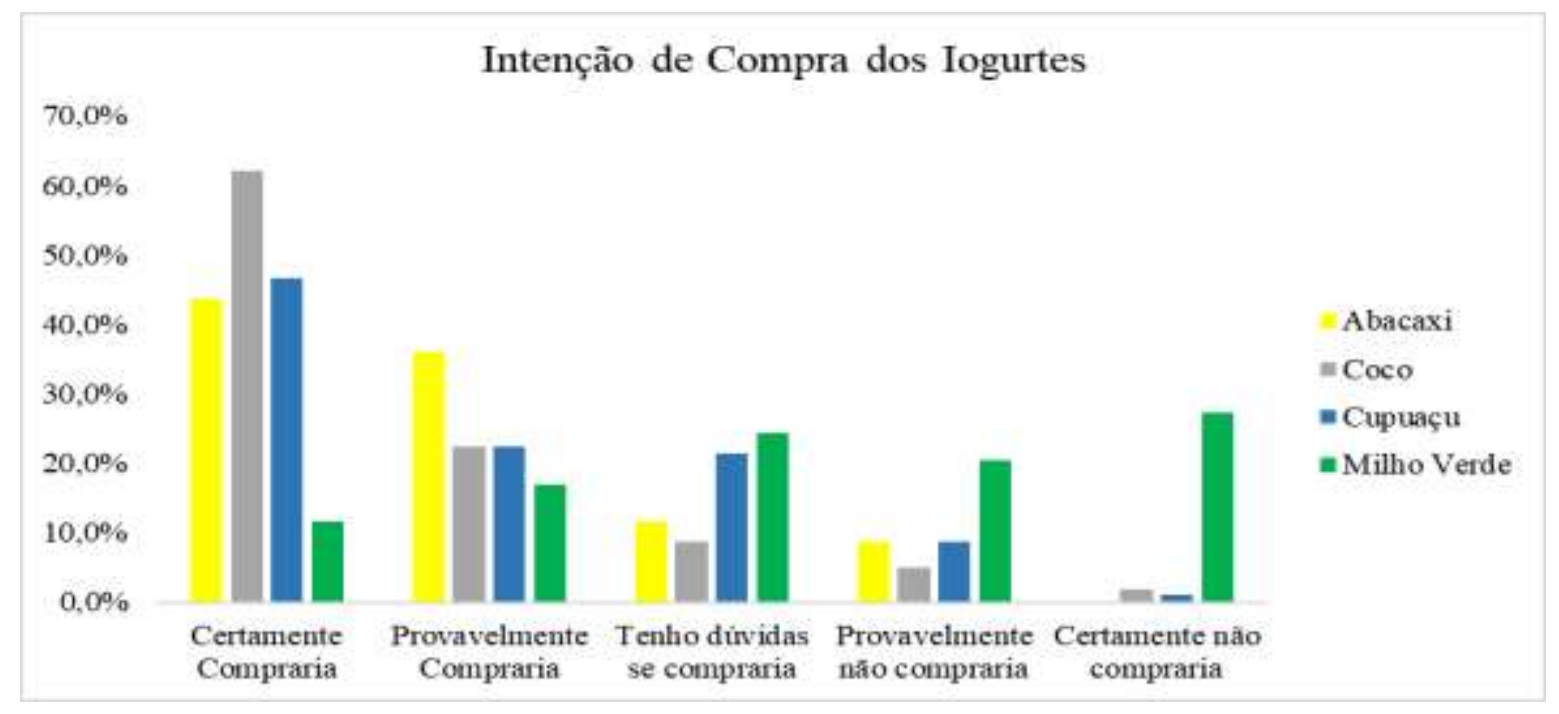

Fonte: Própria (2019)

Cunha et al. (2009) destacam que os atributos sensoriais como o aroma, textura e o sabor são os principais determinantes na aceitação, intenção de compra e preferência dos produtos alimentícios.

Conforme Souza (2013), essa predominância de valores de intenção de compra (certamente compraria e provavelmente compraria) mostra o potencial de mercadológico dos iogurtes sabores abacaxi, coco e cupuaçu.

Já o sabor de milho verde teve alto índice de rejeição pelos consumidores, chegando à $71,9 \%$ (certamente não compraria, provavelmente não compraria e tenho dúvida se compraria). 
Essa rejeição está diretamente relacionada com os atributos avaliados, uma vez que o índice de aceitabilidade desse produto se apresentou baixo do mínimo para ser considerado aceito.

\section{Análise de mercado}

Os dados obtidos na pesquisa de mercado mostram a discrepância entre os preços de iogurtes das três principais marcas comercializadas nos supermercados de Castanhal e o preço dos iogurtes comercializados na sede CASP.

A variação de preço entre os iogurtes de $900 \mathrm{~g}$ das três marcas e os iogurtes da CASP chega a $\mathrm{R} \$ 5,89$, como mostra a tabela 01 . Com essa variação de valor em relação a quantidade do produto comercializado, percebe-se que os iogurtes da CASP possuem uma vantagem econômica para os consumidores, frente as demais marcas do mercado. Dessa forma, os produtos da cooperativa têm grande capacidade comercialização.

Tabela 01: valores de iogurte de 900g nos supermercados de grande e pequeno porte (SGP e SPP) de Castanhal.

\begin{tabular}{lccccccc}
\hline \multicolumn{7}{c}{ Valores em reais $(\mathbf{R} \$)$} & de iogurtes comercializados em Castanhal \\
\hline Marcas/900g & SGP1 & SGP2 & SGP3 & SGP4 & SGP5 & SPP1 & SPP2 \\
A & 10,10 & 10,45 & 9,99 & 8,99 & 9,89 & 10,50 & 10,50 \\
B & 9,85 & 9,40 & 9,89 & 8,8 & 9,3 & 9,60 & 9,60 \\
C & 9,95 & 9,95 & 9,19 & 10,89 & 8,99 & 10,40 & 10,40 \\
CASP & 5,00 & 5,00 & 5,00 & 5,00 & 5,00 & 5,00 & 5,00 \\
\hline \multicolumn{7}{c}{ Fonte: Própria (2019) }
\end{tabular}

A tabela 02 mostra os valores dos iogurtes de $170 \mathrm{~g}$ das três principais marcas comercializadas em Castanhal. Pode-se observar que mesmo com 30g a mais, o iogurte da CASP possui o menor preço quando comparado com os demais.

Nessa categoria, a variação de preço entre os iogurtes de $200 \mathrm{~g}$ da CASP e os comercializados nos supermercados chaga a $\mathrm{R} \$ 1,80$. Desse modo, mais uma vez, os produtos da cooperativa possuem vantagens econômicas em relação as outras marcas.

Tabela 02: valores de iogurte de 170g nos supermercados de grande e pequeno porte (SPG e SPP) de Castanhal.

\begin{tabular}{lccccccc}
\hline \multicolumn{7}{c}{ Valores em reais $(\mathbf{R} \$)$} & de iogurtes comercializados em Castanhal \\
\hline Marcas/170g & SGP1 & SGP2 & SGP3 & SGP4 & SGP5 & SPP1 & SPP2 \\
A & 3,15 & 3,32 & 3,00 & 2,48 & 2,69 & 3,10 & 3,30 \\
B & 2,59 & 2,49 & 2,59 & 2,66 & 2,29 & 2,75 & 2,70 \\
C & 2,59 & 2,40 & 2,75 & 2,53 & 2,59 & 3,10 & 3,10 \\
CASP/200g & 1,50 & 1,50 & 1,50 & 1,50 & 1,50 & 1,50 & 1,50 \\
\hline \multicolumn{7}{c}{ Fonte: Própria (2019) }
\end{tabular}


Para Spinelli (2006), o preço é um dos determinantes para a escolha dos produtos pelos compradores. É um dos elementos chave para obterem o volume de vendas desejado e por consequência, tem grande impacto nos lucros da empresa, tendo função fundamental na fidelização do consumidor com a marca do produto.

Quando o cliente percebe que o preço de um produto ou serviço é razoável, ele se sentirá mais satisfeito e manifestará intenções de repetir a compra. Por outro lado, se o consumidor sente que seu sacrifício não vale a pena, ele poderá não repetir a compra, mesmo que esteja satisfeito com a qualidade do produto (BEI, 2001).

Outro ponto que pode influenciar na compra do produto está relacionado a qualidades comerciais desse produto. Desta forma, vale salientar que, os iogurtes da CASP são produtos certificados pela Agência de Devesa Agropecuária do Pará/ADEPARÁ, como Produtos Artesanais comestíveis de origem Animal, registrado pelo $\mathrm{N}^{\circ} 0001 / 002$. Outro fator que garante a expansão do mercado é o Serviço de Inspeção Estadual (SIE) que a agroindústria da CASP apresenta, o que influencia diretamente no acesso a mercados em todo o território do Estado do Pará.

Assim, percebe-se que a qualidade sensorial dos iogurtes sabores, abacaxi, coco e cupuaçu e o preço desses produtos são fatores que poderão satisfazer os consumidores e fazelos comprar novamente, fidelizando esses clientes e trazendo, assim, uma alternativa de comercialização para os produtos da CASP.

\section{Conclusões}

Os iogurtes sabores abacaxi, coco e cupuaçu apresentaram índice de aceitabilidade acima de $80 \%$, sendo classificados como "aceitos". As intenções de compra desses iogurtes apresentaram porcentagens significativas, estando entre 68,9\% e 84,4\%. Outrossim, os preços dos iogurtes comercializados em Castanhal estão bem acima do preço de comercialização da CASP, de modo ser vantajoso esse fato para a Cooperativa. Portanto, por apresentarem alto potencial mercadológico, os iogurtes da CASP são viáveis para serem inseridos no mercado consumidor, como forma alternativa de comercialização da cooperativa.

Por outro lado, o iogurte sabor milho verde apresentou baixo índice aceitabilidade com $65,94 \%$, sendo classificado como "não aceito" e a intenção de compra desse iogurte mostrou que o mesmo foi rejeitado pelos consumidores. Dessa forma, esse produto é inviável para a inserção no mercado consumidor. 


\section{Referências}

ABNT. ASSOCIAÇÃO BRASILEIRA DE NORMAS TÉCNICAS. NBR 12806: análise sensorial dos alimentos e bebidas - terminologia. Rio de Janeiro, 1993.

ANDRADE, V. D.; OLIVEIRA, R. L.; MATOS, H.; PORTO, T. S.; PORTO, C. S. Aceitação sensorial de iogurte artesanal simbiótico. Revista Brasileira de Agrotecnologia (BRASIL), v.7, n. 2, pp. 411-419, 2017.

ANTÔNIO, Paulo; DUTRA, Karen Estefan. Pesquisa de mercado: ferramenta norteadora no processo decisório que antecede a tomada de decisão. Revista Eletrônica da Faculdade Metodista Granbery. 2008.

ANTUNES, Adriane Elisabete Costa; CAZETTO, Thalita Filier; BOLINI, Helena Maria André. Iogurtes desnatados probióticos adicionados de concentrado protéico do soro de leite: perfil de textura, sinérese e análise sensorial. Alimentos e Nutrição. Araraquara, v. 15, n. 2, p. 107-114, 2008.

BASTOS, G. A.; PAULO, E. M.; CHIARADIA, A. C. N. Aceitabilidade de barra de cereais potencialmente probiótica. Campinas, v. 17, n. 2, p. 113-120. 2014.

BARBOZA, Liane Maria Vargas; FREITAS, Renato J. S; WASZCZYNSKYJ, Nina. Desenvolvimento de produtos e análise sensorial. Brasil alimentos, v. 18, p. 34-35, 2003.

BEI, L.; CHIAO, Y. An Integrated Model for the Effects of Perceived Product, Perceived Service Quality, and Perceived Price Fairness on Consumer Satisfaction and Loyalty. Journal of Consumer Satisfaction, Dissatisfaction and Complaining Behavior, v. 14, p.125-140, 2001.

BRASIL. Ministério de Agricultura, Pecuária e Abastecimento. Regulamento técnico de identidade e qualidade de leites fermentados. Instrução normativa $n^{\circ} 46$, de 23 de outubro de 2007.

CUNHA, C. de S.; CASTRO, C. F. de; PIRES, C. V.; PIRES, I. S. C.; HALBOTH, N. V.; MIRANDA, L. S. Influência da textura e do sabor na aceitação de cremes de aveia por indivíduos de diferentes faixas etárias. Alimentos e Nutrição. Araraquara. 2009.

DUTCOSKY, S. D. Análise sensorial de alimentos. 2 eds. ver. e ampl. Curitiba: Champagnat. 239 p. 2007.

GOMES, R. G.; PENNA, A. L. B. Características reológicas e sensoriais de bebidas lácteas funcionais. Ciências Agrárias, Londrina, v. 30, n. 3, p. 629-646, 2009.

IBGE. Cidades e Estados. Castanhal, 2018. Disponível em: https://www.ibge.gov.br/cidadese-estados/pa/castanhal.html. Acessado em: 22 de setembro de 2019.

MALHOTRA, N. K. Pesquisa de Marketing: uma orientação aplicada. 3. ed. Porto Alegre: Bookman, 2001. 
MINIM, V. P. R. Análise Sensorial - estudo com consumidores. Viçosa: UFV, pag. 308, 2010 .

MILAGRES, Maria Patrícia et al. Análise físico-química e sensorial de doce de leite produzido sem adição de sacarose. Ceres, v. 57, n. 4, 2015.

MORAES, P. C. B. T. Avaliação de iogurtes líquidos comerciais sabor morango: estudo de consumidor e perfil sensorial. Dissertação de Mestrado Universidade Estadual de Campinas, Campinas. 128p. 2004.

POLIGNANO, Luiz A. Castanheira; DRUMOND, Fátima Brant. O papel da pesquisa de mercado durante o desenvolvimento de produtos. In: $3^{\circ}$ Congresso Brasileiro de Gestão de Desenvolvimento de Produtos, Florianópolis. Anais, UFSC. 2001.

REIS, R. C.; MINIM, V. P. R.; DIAS, B. R. P.; CHAVES, J. B. P.; MINIM, L. A. Impacto da utilização de diferentes edulcorantes na aceitabilidade de iogurte "light" sabor morango. Alimentos e Nutrição Araraquara, v. 20, n. 1, p. 53-60, 2009.

RUAS, Robertho Marconi Santos. GUERRA, Gutemberg Armando Diniz. FURTADO, Diego Corrêa. ASSIS, William Santos de. Pressões e oposições contra pequenos criadores familiares de gado bovino leiteiro da zona periurbana do Município de Castanhal (Pará, Brasil - Amazônia Oriental). Mundo Agrário, 15 (30), dezembro 2014. Disponível em: http://www.mundoagrario.unlp.edu.ar/article/download/4483/6439. Acessado em 10 de setembro de 2019.

SILVA, A, C, S, M. Introdução à Análise sensorial de Gêneros alimentícios e sua aplicação na indústria alimentar. Instituto de ciências biomédicas Abel Salazar. Porto, 2015.

SOUZA, A. A.; RODRIGUES, A. J.; ARAÚJO, A. J. B.; SANTOS, I. R. A.; ARAÚJO, F. P. Elaboração, aceitabilidade e intenção de compra de iogurte saborizado com polpa de maracujá do mato. In: Embrapa Semiárido-Artigo em anais de congresso (ALICE). In: congresso norte e nordeste de pesquisa e inovação tecnológica, 8., 2013, Salvador. Pesquisa e inovação para o desenvolvimento do Brasil. Salvador: Instituto Federal de Educação, Ciência e Tecnologia Baiano: SETEC, 2013.

SPAREMBERGER, Ariosto; ZAMBERLAN, Luciano. Marketing Estratégico. UNIVERSIDADE REGIONAL DO NOROESTE DO ESTADO DO RIO GRANDE DO SUL - UNIJUÍ. Ijuí, Rio Grande do Sul, Brasil. 2008.

SPINELLI, Paula Bulamah. Análise da formação de preço de produtos: um estudo multicasos em supermercados. 2006, 166p. Tese (Mestrado em Administração de Organizações do Departamento de Administração da Faculdade de Economia), Programa de Pós-graduação em Administração de Organizações do Departamento de Administração da Faculdade de Economia, Universidade de São Paulo Faculdade de Economia, Administração e Contabilidade de Ribeirão Preto, Ribeirão Preto, 2006. 
TEIXEIRA, Lílian Viana. Análise sensorial na indústria de alimentos. Revista do Instituto de Laticínios Cândido Tostes, v. 64, n. 366, p. 12-21, 2009.

TINICO, M. A. C.; RIBEIRO, J. L. D. Estudo qualitativo dos principais atributos que determinam a percepção de qualidade e de preço dos consumidores de restaurantes a la carte. Gest. Prod., São Carlos, v. 15, n. 1, p. 73-87, 2008.

TRENTIN, Bianca Cristina; MATUSZAK, Alexandre Ramos; DEINA, Carolina; SCHMIDT Carla Adriana Pizarro. Aplicação da escala do ideal na avaliação sensorial comparativa de caramelos tipo toffee. Atena Editora. 2018. 